\title{
Dez anos de doação de córneas no Banco de Olhos do Hospital São Paulo: perfil dos doadores de 1996 a 2005
}

\author{
Ten years of corneal donation to the Hospital São Paulo Eye Bank: \\ characteristics of cornea donors from 1996 to 2005
}

\author{
Consuelo Bueno Diniz Adán ${ }^{1}$ \\ Amanda Rocha Diniz ${ }^{2}$ \\ Débora Perlatto ${ }^{3}$ \\ Flávio Eduardo Hirai ${ }^{4}$ \\ Elcio Hideo Sato ${ }^{5}$
}

Trabalho realizado no Banco de Olhos do Hospital São Paulo da Universidade Federal de São Paulo UNIFESP.

Diretora Médica Adjunta do Banco de Olhos do Hospital São Paulo da Universidade Federal de São Paulo UNIFESP - São Paulo (SP) - Brasil

${ }^{2}$ Médica residente do $1^{\circ}$ Ano - Clínica Médica UNIFESP - São Paulo (SP) - Brasil.

3 Tecnóloga Oftálmica pela UNIFESP - São Paulo (SP) Brasil.

${ }^{4}$ Médico oftalmologista e Pós-graduando (doutorado) pela UNIFESP - São Paulo (SP) - Brasil.

Diretor Médico do Banco de Olhos do Hospital São Paulo da UNIFESP - São Paulo (SP) - Brasil.

Endereço para correspondência: Consuelo Bueno Diniz Adán. Av. Onze de Junho, 737/224 - São Paulo (SP) CEP 04041-052

E-mail: gilmd@uol.com.br

Recebido para publicação em 25.04.2007

Última versão recebida em 27.06.2007

Aprovação em 22.12.2007

Nota Editorial: Depois de concluída a análise do artigo sob sigilo editorial e com a anuência do Dr. José Américo Bonatti sobre a divulgação de seu nome como revisor, agradecemos sua participação neste processo.

\begin{tabular}{|l|}
\hline RESUMO \\
\hline Histórico: Apesar dos esforços que vêm sendo realizados mais recen- \\
temente, a falta de córneas para transplantes ainda é uma realidade no \\
Brasil,principalmente em algumas regiões. O Banco de Olhos do Hospital \\
São Paulo tem como objetivo garantir a qualidade e conservação dos \\
tecidos oculares humanos para disponibilizá-los para transplantes. A \\
qualidade do tecido encontra-se diretamente ligada a todos os processos \\
realizados pela equipe do banco de olhos, a partir da seleção dos \\
doadores. Objetivo: Conhecero perfil dos doadores de córneas do Banco \\
de Olhos do Hospital São Paulo num período de dez anos. Métodos: \\
Estudo retrospectivo de fichas de doadores, no período de janeiro de \\
1996 a dezembro de 2005. Resultados: Chegaram ao Banco de Olhos do \\
Hospital São Paulo 3.624 córneas. A idade média dos doadores foi de 56,8 \\
anos. A faixa etária com maior doação foi de 70-79 anos. A causa mortis \\
mais freqüente foi doença cardiovascular, seguida por neoplasias, doen- \\
ças respiratórias e trauma. O tempo "enucleação" foi em média de 3,8 \\
horas e o tempo "preservação" foi em média de 3,6 horas. A maioria dos \\
tecidos foi preservada em meios Optisol GS ${ }^{\circledR}$.Os doadores jovens tiveram \\
maior proporção de córneas consideradas de qualidade "Excelente" ou \\
"Boa". Conclusão: Ao longo do período estudado de 10 anos, houve \\
tendência de redução no recebimento de tecidos de outros bancos de \\
olhos e progressivo aumento na captação e preservação de tecidos pela \\
equipe do próprio Banco, com redução significativa no tempo de pre- \\
servação dos tecidos. Os doadores foram, na maioria, do sexo masculino \\
e as doenças cardiovasculares lideraram as causas de óbito. Apesar da \\
maioria das córneas serem provenientes de doadores acima de 60 anos, \\
o maior percentual de aproveitamento de córneas para transplantes \\
ópticos foi de doadores jovens. \\
\hline
\end{tabular}

Descritores: Bancos de Olhos; Transplante de córnea; Endotélio da córnea/patologia; Transplante de tecidos; Doadores de tecidos/estatística \& dados numéricos

\section{INTRODUÇÃO}

As doenças da córnea, segunda causa de cegueira reversível no mundo, atingem uma população jovem e ativa, levando a importante perda econômica e social. A falta de tecidos e de Bancos de Olhos capacitados para fornecer córneas em número e qualidade adequada para transplantes ainda é uma realidade entre nós, apesar dos esforços que vêm sendo feitos. 
O Banco de Olhos do Hospital São Paulo (BOHSP) tem sede no Hospital São Paulo, serviço terciário, ligado à Universidade Federal de São Paulo/Escola Paulista de Medicina (UNIFESP/EPM), e segue os padrões internacionais para captação e preservação de córneas, baseados nas normas da Associação Panamericana de Bancos de Olhos (APABO) ${ }^{(1)} \mathrm{e}$ da Associação Americana de Bancos de Olhos (EBAA) ${ }^{(2)}$.

Devido à escassez de estudos sobre Bancos de Olhos no Brasil, o objetivo desde trabalho foi avaliar o perfil dos doadores de córneas do BOHSP num período de 10 anos.

\section{MÉTODOS}

Este estudo retrospectivo foi aprovado pelo Comitê de Ética em Pesquisa da UNIFESP sob o número 0936/06.

Realizamos levantamento manual dos dados a partir de fichas de doadores de córneas que foram distribuídas via BOHSP (córneas captadas pelo próprio BOHSP, Banco de Olhos de Sorocaba (BOS) ou por outros hospitais, como Santa Casa de Santos, Hospital Santa Marcelina, Hospital do Servidor Público do Estado de São Paulo) no período de janeiro de 1996 a dezembro de 2005.

A partir dos formulários dos doadores obtivemos informações quanto à idade, sexo, causa mortis, intervalo entre o óbito e a captação e preservação da córnea, além do destino dado ao tecido, ou seja, disponibilização ou não para enxerto e tipo de enxerto.

O tempo "enucleação" é o número de horas entre o óbito do doador e a retirada dos globos oculares. O BOHSP realiza captações em doadores até 6 horas após o óbito ou até 24 horas, caso o corpo esteja sob refrigeração ou ainda em doador de múltiplos órgãos. O tempo "preservação" é o número de horas entre a retirada dos globos oculares e o processamento do tecido, ou seja, a preservação da córnea.

O BOHSP submete os tecidos à avaliação biomicroscópica em dias subseqüentes por dois examinadores para sua classificação final em "Excelente", "Bom", "Razoável", "Ruim" ou "Inaceitável". As três primeiras categorias permitem que o tecido seja utilizado em enxertos para fins ópticos. Já os tecidos classificados como "Ruins" são destinados a enxertos tectônicos e os tecidos considerados "Inaceitáveis" são descartados.

$\mathrm{Na}$ análise estatística utilizou-se o teste $\mathrm{t}$ de Student para as variáveis contínuas e o teste de qui-quadrado para as variáveis categóricas. Para medir a significância das tendências aplicou-se o teste de Cochran-Armitage. Foram considerados significativos valores de $\mathrm{p}<0,05$.

\section{RESULTADOS}

Durante os 10 anos do estudo (1996-2005) passaram pelo BOHSP 3.624 córneas. A falta de uniformidade nos dados e registros limitaram a análise a 2.787 doações. A avaliação dos dados foi dividida em dois períodos de cinco anos para comparação. Observou-se que na primeira metade (1996-2000), ocorreram 740 doações. Já no segundo período de cinco anos (2001-2005) o número de doações aumentou para 2.047.

\section{Faixa etária}

Quanto à faixa etária dos doadores, a média foi de $56,8 \pm$ 20,5 anos para o período de 10 anos; $61,9 \pm 19,4$ anos no período de 1996-2000 e 54,9 \pm 20,6 anos para o período de 2001-2005 (Tabela 1). O doador mais jovem foi de um ano e o mais idoso, de 102 anos; com mediana de 60 anos. A faixa etária que apresentou maior percentual de doação foi de $70-79$ anos $(18,9 \%)$, seguida pela faixa dos 60-69 anos $(18,6 \%)$ (Figura 1).

\section{Sexo}

Quanto à distribuição relacionada ao sexo, verificou-se que $56,8 \%$ dos tecidos eram provenientes de doadores do sexo masculino. Não houve variação significativa quanto ao sexo dos doadores entre os períodos de cinco anos (Tabela 1).

\section{Procedência dos tecidos}

Entre 1996-2000, 50,3\% dos tecidos que chegaram ao BOHSP eram provenientes do Banco de Olhos de Sorocaba, seguidos por captações feitas pelo próprio BOHSP $(27,6 \%)$, tecidos procedentes de Banco de Olhos internacionais $(13,9 \%)$ e de outros bancos de olhos $(8,2 \%)$. Nos cinco anos seguintes (2001-2005), os tecidos procedentes de captações feitas pelo próprio BOHSP somaram $56,4 \%$ do total, contra os $13,2 \%$ originados do BOS, de BO Internacionais $(0,6 \%)$ e de outros bancos de olhos (29,8\%) (Tabela 1).

\section{Causa mortis}

Quanto às causas do óbito, agrupou-se em seis grupos, baseado no Código Internacional das Doenças (CID 10). As causas mais freqüentes de óbito dos doadores no período de 10 anos foram doenças cardiovasculares (40\%), seguidas por neoplasias $(15,9 \%)$, doenças do aparelho respiratório $(14,9 \%)$, causas externas/traumas $(13,9 \%)$ e doenças infecciosas e parasitárias $(6,5 \%)$. Outras causas foram responsáveis por $8,8 \%$ dos óbitos dos doadores no período de dez anos. Diferentemente dos primeiros cinco anos do levantamento, o óbito por causas externas foi responsável por 16,3\% dos óbitos, enquanto que nos primeiros cinco anos respondeu por $5,8 \%$ de todos os óbitos dos doadores $(\mathrm{p}<0,01)$ (Tabela 1$)$.

\section{Intervalos óbito/captação e captação/preservação}

O tempo "enucleação" foi em média de 3,8 horas ( 3,7 h nos primeiros cinco anos e $3,4 \mathrm{~h}$ no segundo período de cinco anos).

O tempo "preservação" foi em média de 3,6 horas $(4,4$ h no período de 1996-2000 e 3,4 h no período de 2001-2005) (Tabela 1).

\section{Processamento dos tecidos}

Neste estudo, observou-se que a preservação dos tecidos ocorreu em $99,7 \%$ dos casos e apenas $0,3 \%$ foram utilizados diretamente da câmara úmida. Entre 1996 e 2000, o meio Optisol $\mathrm{GS}^{\circledR}$ foi utilizado em $85,6 \%$ dos casos. Já entre 2001-2005, 


\begin{tabular}{|c|c|c|c|c|}
\hline Características & $1996-2005 \quad(n=2787)$ & $1996-2000 \quad(n=740)$ & $2001-2005 \quad(n=2047)$ & Valor de $\mathrm{p}^{*}$ \\
\hline Idade (anos) & $56,8 \pm 20,5$ & $61,9 \pm 19,4$ & $54,9 \pm 20,6$ & $<0,01$ \\
\hline Sexo (masculino) & 56,8 & 56,6 & 57,0 & 0,88 \\
\hline Procedência (\%) & & & & $<0,01$ \\
\hline BO HSP & 48,5 & 27,6 & 56,4 & \\
\hline BO Sorocaba & 23,4 & 50,3 & 13,2 & \\
\hline BO Internacional & 4,2 & 13,9 & 0,6 & \\
\hline Outros & 23,9 & 8,2 & 29,8 & \\
\hline CID (\%) & & & & $<0,01$ \\
\hline I (doenças infecciosas e parasitárias) & 6,5 & 3,8 & 7,3 & \\
\hline II (neoplasias) & 15,9 & 13,8 & 16,6 & \\
\hline IX (doenças do aparelho circulatório) & 40,0 & 44,8 & 38,6 & \\
\hline X (doenças do aparelho respiratório) & 14,9 & 12,5 & 15,6 & \\
\hline $\mathrm{XX}$ (causas externas) & 13,9 & 5,8 & 16,3 & \\
\hline Outros & 8,8 & 19,3 & 5,6 & \\
\hline Tempo enucleação (horas) & $3,8 \pm 2,9$ & $3,7 \pm 2,5$ & $3,9 \pm 2,9$ & 0,14 \\
\hline Tempo preservação (horas) & $3,6 \pm 4,8$ & $4,4 \pm 5,5$ & $3,4 \pm 4,6$ & $<0,01$ \\
\hline Meio $(\%)$ & & & & $<0,01$ \\
\hline Optisol GS ${ }^{\circledR}$ & 92,2 & 85,6 & 94,3 & \\
\hline Outros & 4,9 & 11,1 & 3,0 & \\
\hline Glicerina & 2,6 & 2,7 & 2,5 & \\
\hline Câmara úmida & 0,3 & 0,6 & 0,2 & \\
\hline
\end{tabular}

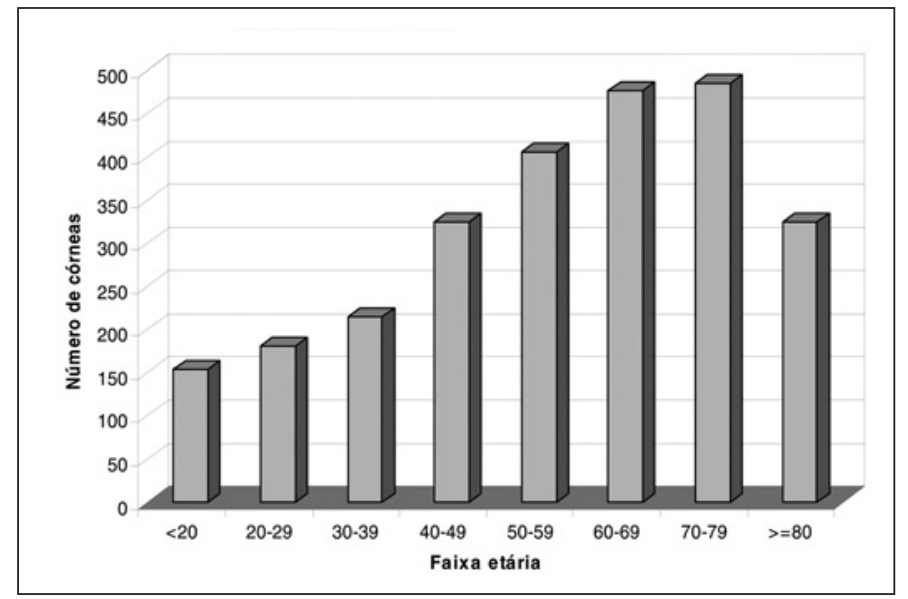

Figura 1 - Distribuição do número de córneas doadas segundo faixa etária no período de 1996-2005

94,3\% das córneas foram preservadas naquele meio. De modo geral, nesses 10 anos de estudo, o meio Optisol GS ${ }^{\circledR}$ foi utilizado em 92,2\% dos casos. Outros meios de preservação de córneas como Eusol $^{\circledR}$, Ophthalmos $^{\circledR}$, Dexsol $^{\circledR}$, e Likorol ${ }^{\circledR}$ foram pouco utilizados. A preservação em glicerina para uso em transplantes tectônicos permaneceu constante nesse período, em aproximadamente 2,6\% dos casos (Tabela 1 ).

\section{Qualidade e aproveitamento dos tecidos}

Quanto ao aproveitamento dos tecidos, no período de 1996 a 2000, 57,2\% das córneas foram utilizadas para trans- plantes ópticos; 25,4\% para enxertos tectônicos e 17,4\% dos tecidos foram descartados.

No período de 2001-2005, 30\% das córneas foram utilizadas para transplantes ópticos e $15 \%$ para tectônicos. Nesse período, cerca de $58 \%$ das córneas foram avaliadas como satisfatórias para enxertos ópticos (excelente, bom, regular). Aproximadamente $30 \%$ das córneas foram utilizadas para transplantes ópticos. Os tecidos descartados perfizeram aproximadamente $49 \%$.

Quanto à faixa etária, no período de 10 anos (1996-2005), observou-se que a faixa dos 20-29 anos foi a que apresentou maior porcentagem de aproveitamento para enxertos ópticos (Figura 2). Entre 2001-2005, a faixa etária < 20 anos apresentou a maior porcentagem de córneas consideradas excelentes/boas.

\section{DISCUSS ÃO}

O Banco de Olhos do Hospital São Paulo (BOHSP) foi fundado em 1991 e é uma entidade sem fins lucrativos. Atualmente, a instituição realiza busca ativa de doações dentro do próprio hospital, realiza captações em hospitais públicos e privados, necrotérios, Instituto Médico-Legal e domicílios localizados na área de sua competência de atuação, conforme a legislação vigente. Nessa área estão aproximadamente seis milhões de pessoas ${ }^{(3)}$. Durante a década de 90 e até 2005, além destas fontes, chegavam ao BOHSP córneas já processadas, provenientes de outros Bancos de Olhos localizados no Estado de São Paulo, como por exemplo, o Banco de Olhos de Sorocaba para que fossem reavaliadas e distribuídas aos pa- 


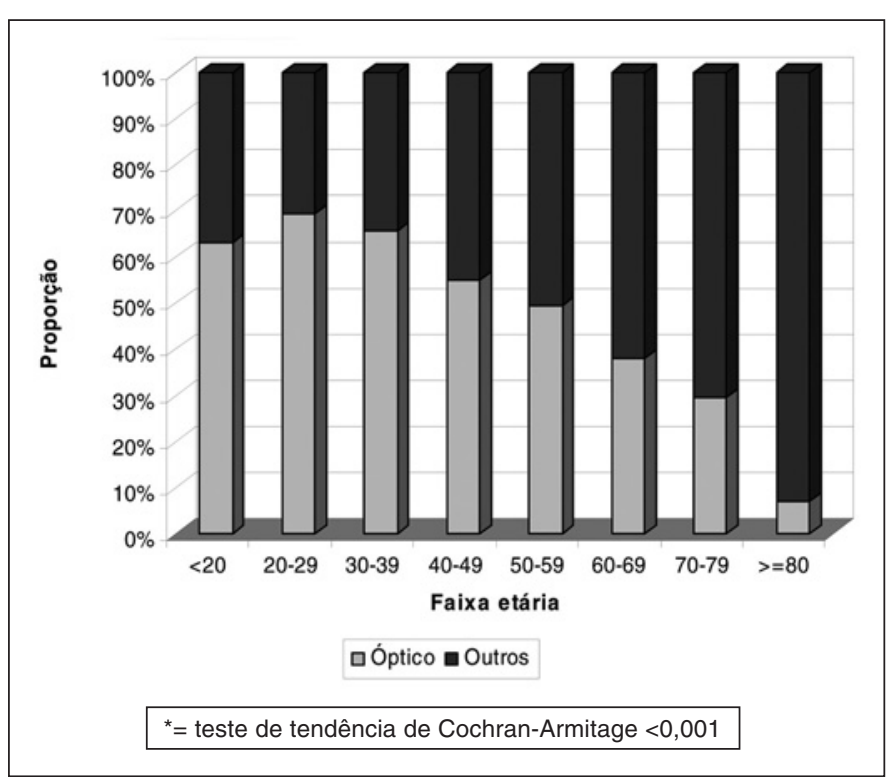

Figura 2 - Faixa etária de melhor aproveitamento (transplante óptico) no período $1996-2005^{*}$

cientes da Instituição que aguardavam na lista por um transplante de córnea. Ainda na década de 90, por escassez de tecidos, o BOHSP recebia córneas de bancos de olhos norteamericanos.

Neste estudo, a maioria dos doadores tinha idade acima de 60 anos, semelhante aos resultados de outros bancos de olhos. Na verdade, a maior proporção de doações ocorreu entre 70 a 79 anos. Num estudo realizado na mesma Instituição, na década de 90, a maioria dos doadores também se encontrou em faixas etárias acima de $60 \operatorname{anos}^{(4)}$. No Banco de Olhos de Minnesota, as doações mais freqüentes provinham de indivíduos entre $60 \mathrm{e}$ 69 anos, seguidos pelos doadores de 70 a 75 anos de idade ${ }^{(5)}$. Num estudo australiano, observou-se que dois terços dos doadores estavam na faixa entre 54 a $64 \operatorname{anos}^{(6)}$.

As idades mínima e máxima de um doador para utilização do tecido variam conforme as Normas Médicas de cada banco de olhos. Neste levantamento a menor idade foi de um ano. Atualmente, em nossa instituição, são captados tecidos de doadores acima de dois anos de idade, em decorrência das dificuldades técnicas cirúrgicas inerentes aos tecidos de crianças de faixa etária mais baixa. Na literatura, há Bancos de Olhos em que a idade mínima para doação chega até a $10 \operatorname{anos}^{(7)}$, mais alta do que a maioria de bancos de olhos brasileiros.

No BOHSP não existe limite superior de idade para captação. No período do levantamento, nosso doador mais idoso tinha 102 anos. A idade avançada costuma ser um fator limitante já que a maioria dos cirurgiões prefere não utilizar córneas de pacientes acima de 75 anos $^{(4,7-9)}$.

Essa idade é arbitrária, uma vez que a idade do doador não parece estar relacionada com a sobrevivência do enxerto ${ }^{(7)}$. Deve-se reavaliar este aspecto, uma vez que a sobrevida da população está aumentando e a não utilização dos tecidos baseada apenas na idade, pode gerar aumento significativo no descarte de tecidos ${ }^{(5,8)}$. Por outro lado, doadores idosos podem apresentar história de cirurgia intra-ocular prévia e doenças corneanas, como a guttata, condições que poderiam limitar o uso de córneas em transplantes.

Quando se comparou a idade média do doador entre os períodos de cinco anos, observou-se redução na idade média do doador (61,9 anos entre 1996-2000 e 54,9 anos entre 2001$2005)(\mathrm{p}<0,01)$. Isto poderia estar relacionado ao aumento de óbitos por causas externas (traumatismo) e doenças do aparelho circulatório nesse período.

$\mathrm{Na}$ distribuição dos doadores por sexo, observou-se que $56,8 \%$ eram do sexo masculino, sem que houvesse significância estatística neste dado. A preponderância de doadores homens é citada nos resultados publicados em outro estudo, possivelmente porque os homens morrem mais jovens que as mulheres devido a trauma e doenças cardiovasculares ${ }^{(7)}$.

De fato, as doenças cardiovasculares foram a mais freqüente causa de óbito dos doadores, seguidas pelas neoplasias e causas externas (trauma). Em estudo anterior, realizado na mesma Instituição, também foram as causas cardio-respiratórias as mais frequientes ${ }^{(4)}$. Dados semelhantes foram encontrados por outros autores ${ }^{(5-6)}$.

Ao se comparar os dois períodos de estudo, observamos que houve aumento significativo nas causas externas e doenças infecciosas e neoplasias (Tabela 1). $\mathrm{O}$ aumento nas causas externas (trauma) pode estar relacionado ao modo de vida de metrópole, como a cidade de São Paulo, onde a violência pode levar a número progressivo de perda de vidas. Já o aumento das causas infecciosas pode ser explicado pela detecção de maior número de casos, e triagem sorológica mais acurada.

Quando se observa a procedência dos tecidos, verificou-se que neste período houve redução significativa da distribuição de córneas procedentes do exterior, diferentemente do observado em estudo prévio ${ }^{(4)}$. Naquela época, a falta de Banco de Olhos nacionais capacitados promoveu a criação de programa de "Banco de Olhos Irmãos" que facilitava o intercâmbio de tecidos procedentes de Bancos de Olhos americanos. As córneas procedentes do Banco de Olhos de Sorocaba, instituição com tradição na captação de tecidos, também tiveram participação reduzida nas estatísticas do nosso banco de olhos, já que nos últimos cinco anos do levantamento o BOHSP se transformou em agente captador em vez de ser apenas redistribuidor. Outros hospitais tiveram sua participação aumentada no envio de tecidos ao BOHSP para processamento dos mesmos. Esta participação deve aumentar ainda mais, uma vez que tem havido maior divulgação, campanhas, além da legislação atual, que estimula o surgimento e a participação de Equipes e Comissões intra-hospitalares para aumentar a captação de tecidos. Também é importante ressaltar que acreditamos que o expressivo aumento de captação própria do BOHSP no período de 2001 a 2005 foi um impacto direto da estruturação de equipe própria permanente de captação, exclusivamente ligada ao Banco de Olhos, e não mais dependente de residentes ou estagiários temporários. 
Acreditamos que a agilidade dos processos numa instituição como Banco de Olhos é necessária tendo em vista que a preservação da vitalidade e qualidade dos tecidos é também função do tempo. Intervalos prolongados entre o óbito e a captação e entre a captação e preservação podem justificar a não liberação do tecido para transplantes ópticos, pelo risco de falência do enxerto. Apesar desta possibilidade, um outro estudo realizado na Instituição não mostrou diferença estatística entre os diferentes intervalos de tempo e o aumento nas taxas de falência primária do botão transplantado ${ }^{(10)}$. De forma geral, o tempo "enucleação" foi de 3,8 ( $\pm 2,9$ horas); o tempo "preservação" foi de 3,6 \pm (4,8 horas). Nos últimos cinco anos do levantamento houve significativa redução do número de horas para a preservação dos tecidos (Tabela 1). Isto se deu, provavelmente, pela melhoria de condições internas do BOHSP, principalmente pela profissionalização do pessoal, conscientização e motivação da equipe em decorrência da importância do trabalho realizado, além do suprimento do material necessário. Já a não redução do tempo enucleação pode ser explicada, nos casos de captação externa ao HSP, por diversos fatores, como a dificuldade de transporte para se chegar ao doador, grandes distâncias percorridas, percursos com tráfego intenso e congestionamento, próprios da cidade. Em alguns bancos de olhos, onde a captação pode ocorrer em áreas rurais, com dezenas de quilômetros de distância, este problema também se torna evidente ${ }^{(5)}$. Nos óbitos dentro do próprio HSP, a demora na chegada dos familiares para entrevista familiar é um dos fatores que contribui para o retardo na enucleação. Apesar de complexos e multifatoriais, acreditamos que estes parâmetros possam ser melhorados com aprimoramento do serviço.

O BOHSP realiza a preservação das córneas fazendo a excisão com aba escleral de $3 \mathrm{~mm}$, sob condições assépticas, em capela de fluxo laminar e armazena os tecidos em meio de preservação sob refrigeração de $2^{\circ}$ a $8^{\circ} \mathrm{C}^{(1)}$. Os tecidos são liberados para o uso após informação sobre a negatividade das sorologias das amostras sangüíneas e ausência de contaminação biológica do meio. Casos de retirada in situ da córnea constituem situações raras, e caso não preencham os quesitos de esterilização, algumas vezes não são utilizados em receptores. A preservação em glicerina também pode ocorrer em eventuais situações, como para o armazenamento de tecidos cuja qualidade justifica apenas o uso tectônico.

No período de dez anos o meio Optisol GS ${ }^{\circledR}$ Bausch and Lomb, Rochester, NY) foi utilizado em 92,2\% dos casos; outros meios $\left(\right.$ Ophthalmos ${ }^{\circledR}$, Eusol $^{\circledR}$, Dexsol $^{\circledR}$ e Likorol $^{\circledR}$ ) foram usados em 4,9\% dos casos. Quando os períodos de cinco anos foram comparados, observou-se o aumento significativo na utilização do meio Optisol ${ }^{\circledR}$, que é padronizado em virtude de sua qualidade, e a redução da utilização de outros meios. A preservação em glicerina permaneceu constante nesse período, aproximadamente em 2,6\% dos casos.

Apesar de não traduzir diretamente o estado funcional do mosaico endotelial, a avaliação biomicroscópica dos tecidos pré e pós-preservação e a análise das células endoteliais em número e forma, constituem pilares para a classificação e liberação dos tecidos para transplantes ópticos ou tectônicos.

O BOHSP libera para transplantes ópticos apenas as córneas cuja contagem de células endoteliais é maior ou igual a 2.000 células $/ \mathrm{mm}^{2}$ (média de três medidas).

Estudo de alguns autores referem que córneas transplantadas com a contagem de 2.000 células $/ \mathrm{mm}^{2}$ atingem a contagem considerada de viabilidade crítica de 500 células $/ \mathrm{mm}^{2} \mathrm{com}$ cerca de 20 anos pós-transplante ${ }^{(11)}$.

Densidades endoteliais maiores podem ser requeridas, conforme as normas médicas de cada banco de olhos $(5,7)$. O aproveitamento dos tecidos para enxertos ópticos foi de $57,2 \%$ entre 1996 a 2000; 25,4\% foram utilizados para enxertos tectônicos e 17,4\% descartados. Já entre 2001 a 2005, aproximadamente $30 \%$ das córneas destinaram-se aos transplantes ópticos, aproximadamente $15 \%$ foram destinados a tectônicos e terapêuticos e aproximadamente $50 \%$ não foram utilizados em transplantes por motivos relacionados à qualidade dos tecidos, sorologia ou contaminação. Observou-se que o percentual de tecidos disponíveis para transplantes ópticos (classificados como "excelentes/boas/razoáveis") foi maior do que a porcentagem de enxertos ópticos realizados. Isto pode ter ocorrido porque muitos tecidos, avaliados inicialmente como razoáveis, podem ter perdido qualidade com o decorrer dos dias de preservação. A redução do percentual de córneas liberadas para enxertos ópticos foi significativa e ocorreu, provavelmente, pelo melhor controle de qualidade do $\mathrm{BO}$. O conhecimento de medidas para atingir a segurança e qualidade totais, a satisfação do cliente, o aprendizado com a experiência própria e de outros serviços, têm ensinado aos bancos de olhos serem mais cuidadosos e eficientes.

Neste estudo houve uma tendência estatisticamente significativa (Teste de Cochran-Armitage) de que quanto maior a faixa etária, menor o aproveitamento do tecido para transplante óptico. Ao se analisar o aproveitamento dos tecidos em relação à faixa etária, observou-se que no período de 1996 a 2005, doadores entre 20-29 anos tiveram o melhor aproveitamento (maior porcentagem de transplantes ópticos realizados). Num estudo, o fator idade foi o maior determinante para o uso cirúrgico do tecido. Enquanto $77 \%$ dos tecidos procedentes de doadores menores que 30 foram utilizados em cirurgias, apenas $22 \%$ dos tecidos procedentes de doadores acima de 70 anos tiveram o mesmo fim ${ }^{(9)}$.

Quando se comparou a faixa etária à classificação da córnea em "Excelente/Bom", versus "Outros" ("Razoável”, "Ruim" ou "Inaceitável”), verificou-se que doadores menores de 20 anos tiveram uma maior proporção de córneas excelentes/boas. Repetiu-se a tendência de que quanto maior a faixa etária, menor a proporção de córneas consideradas excelentes/boas $(\mathrm{p}<0,001)$.

No estudo em questão, apesar de não se ter analisado diretamente o número de células endoteliais em relação à faixa etária, a menor porcentagem de córneas boas em faixas etárias 
mais avançadas pode ter ocorrido pela menor densidade endotelial apresentada pelo grupo. Já os doadores mais jovens costumam apresentar as mais altas densidades endoteliais, o que pode ter contribuído para maior porcentagem de córneas classificadas como excelentes e boas neste grupo. Armitage e cols encontraram correlação significativa entre a idade avançada e menor densidade endotelial ${ }^{(8)}$. Entretanto, num outro estudo não se observou diferença significativa na contagem de células endoteliais com o aumento da idade ${ }^{(5)}$.

É importante ressaltar que este estudo apresenta algumas limitações. Uma delas é a falta de informações completas em todas as fichas de doadores. Isto prejudicou uma análise mais abrangente e uniforme, limitando os dados de nossos doadores. O levantamento manual das informações requer tempo, retarda o conhecimento de informações importantes e limita ações corretivas. Faz-se necessário informatização dos arquivos da instituição para o levantamento de maior número de dados, realização de estatísticas e estudos científicos de forma mais eficiente.

\section{CONCLUSÕES}

Observamos que houve aumento no número de córneas disponibilizadas para transplantes pelo BOHSP, principalmente nos últimos anos do período estudado. Além disto, o BOHSP deixou de ser mero distribuidor de tecidos e passou a exercer uma de suas principais atribuições, a de agente captador de córneas.

Outro aspecto positivo evidenciado no estudo foi a redução, de forma significativa, no tempo de preservação dos tecidos, fator relevante para a manutenção da qualidade dos mesmos.

Apesar de a maioria das doações terem sido provenientes de doadores acima de 60 anos, grande parte desses tecidos não pôde ser disponibilizada para transplantes ópticos, como ocorreu com os tecidos de pacientes jovens. Sobre este aspecto, o ideal seria aplicar métodos que avaliassem o estado funcional dos tecidos, com o objetivo de se obter maior aproveitamento dos mesmos, desde que estejam garantidas, sempre, a segurança sanitária dos serviços e das córneas para transplantes.

Estudos desta natureza oferecem a oportunidade de se verificar as falhas, aprender com elas, corrigi-las e adicionar valores e críticas para melhoria contínua nos processos realizados pelo BOHSP.

\section{ABSTRACT}

Background: Despite all efforts towards the improvement of the eye bank system, the shortage of corneal tissue for transplant is still an important issue in Brazil. The Hospital São Paulo Eye Bank aims to provide high-quality ocular tissues for surgery starting with rigorous selection of donors.
Purpose: To investigate the characteristics of cornea donors to the Hospital São Paulo Eye Bank during a 10-year period. Methods: Retrospective analysis of Hospital São Paulo Eye Bank records from January 1996 to December 2005. Results: 3,624 corneas were evaluated by the Hospital São Paulo Eye Bank during this 10-year period. Mean age of donors was 56.8 years the highest proportion being in the 70-79 years age category. The most common cause of death was cardiovascular disease followed by cancer and trauma. Mean "enucleation" and "preservation" times were 3.8 and 3.6 hours, respectively. The number of corneas received by our eye bank from other eye banks decreased substantially whereas the number of corneas harvested by the Hospital São Paulo Eye Bank staff increased. Optisol GS ${ }^{\circledR}$ were the most utilized preservation media and a high proportion of corneas classified as "Excellent" or "Good" came from young donors. Conclusions: In a period of 10 years, there was a decreasing trend in the number of donated corneas provided by other eye banks to the Hospital São Paulo Eye Bank and an increase in the number of corneas harvested and processed by the Hospital São Paulo Eye Bank staff with a significant reduction of preservation time. Most donors were male and the main cause of death was cardiovascular disease. Although a great proportion of donated corneas came from older donors, the majority of corneas used for optical transplants came from younger ones.

Keywords: Eye banks; Corneal transplantation; Endothelium corneal/pathology; Tissue transplantation; Tissue donors/ statistics \& numerical data

\section{REFERÊNCIAS}

1. Associação Panamericana de Banco de Olhos. APABO. Normas médicas. Rio de Janeiro: APABO; 2004.

2. The Eye Bank Association of America. EBAA. Medical Standards [Internet]. Washington: EBAA; 2006 [cited 2008 Jan 24]. Available from: http:// www.restoresight.org/general/about_ebaa.htm

3. São Paulo. Secretaria de Estado de Saúde. Central de Transplantes. Transplante em dados. Distribuição das notificações de doadores potenciais viáveis segundo Organização de Procura de Córneas (OPC) [Internet].São Paulo; 2004. [citado 2008 Jan 24]. Disponível em: http://www.saude.sp.gov.br/ programas_projetos/transplantes/html/transplantes_dados_doadoresOPC.html

4. Sousa LB, Chicani CF, Saud EP, Faria T, Sato EH. Perfil das doações de córneas no BOHSP. Arq Bras Oftalmol. 1997;60(6):608-16.

5. Moyes AL, Holland EJ, Palmon FE, Dvorak JA, Doughman DJ. Tissue utilization at the Minnesota Lions Eye Bank. Cornea. 1995;14(6):571-7.

6. Williams KA, White MA, Badenoch PR, Wedding TR, Alfrich SJ, Sawyer $\mathrm{MA}$, et al. Donor cornea procurement six-year review of the role of the eye bank in South Australia. Aust N J Ophthalmol. 1990;18(1);77-89.

7. Patel HY, Brookes NH, Moffat L, Sherwin T, Ormonde S, Clover GM, et al. The New Zealand National Eye Bank study 1991-2003.A review of the source and management of corneal tissue. Cornea. 2005;24(5):576-82.

8. Armitage WJ, Moss SJ, Easty DL, Bradley BA. Supply of corneal tissue in the United Kingdom. Br J Ophthalmol. 1990;74(11):685-7.

9. Farge EJ, Cox WG, Khan MM. An eye-banking program for selecting donor corneas for surgical distribution. Cornea. 1995;14(6):578-82.

10. Hirai FE, Klattle S, Pacini KM, Sato EH. Falência primária pós-transplante de córnea em serviço universitário. Arq Bras Oftalmol. 2002;65(6):655-7.

11. Armitage WJ, Dick AD, Bourne WM. Predicting endothelial cell loss and longterm corneal graft survival. Invest Ophthalmol Vis Sci. 2003;44(8):3326-31. 